Article

\title{
"School Strike 4 Climate": Social Media and the International Youth Protest on Climate Change
}

\author{
Shelley Boulianne ${ }^{1, *}$, Mireille Lalancette ${ }^{2}$ and David Ilkiw ${ }^{1}$ \\ ${ }^{1}$ Department of Sociology, MacEwan University, Edmonton, T5J 4S2, Canada; E-Mails: bouliannes@macewan.ca (S.B.), \\ ilkiwd2@mymacewan.ca (D.I.) \\ ${ }^{2}$ Department of Communication, Université du Québec à Trois-Rivières, Trois-Rivières, G9A 5H7, Canada; \\ E-Mail: Mireille.Lalancette@uqtr.ca \\ * Corresponding author
}

Submitted: 8 January 2020 | Accepted: 16 March 2020 | Published: 19 May 2020

\begin{abstract}
Beginning in 2018, youth across the globe participated in protest activities aimed at encouraging government action on climate change. This activism was initiated and led by Swedish teenager, Greta Thunberg. Like other contemporary movements, the School Strike 4 Climate used social media. For this article, we use Twitter trace data to examine the global dynamics of the student strike on March 15, 2019. We offer a nuanced analysis of 993 tweets, employing a combination of qualitative and quantitative analysis. Like other movements, the primary function of these tweets was to share information, but we highlight a unique type of information shared in these tweets-documentation of local events across the globe. We also examine opinions shared about youth, the tactic (protest/strike), and climate change, as well as the assignment of blame on government and other institutions for their inaction and compliance in the climate crisis. This global climate strike reflects a trend in international protest events, which are connected through social media and other digital media tools. More broadly, it allows us to rethink how social media platforms are transforming political engagement by offering actors-especially the younger generation-agency through the ability to voice their concerns to a global audience.
\end{abstract}

\section{Keywords}

climate change; environment; march; protest; social media; strike; Twitter; youth

Issue

This article is part of the issue "Youth Digital Participation: Opportunities, Challenges, Contexts, and What's at Stake" edited by Neta Kligler-Vilenchik (Hebrew University of Jerusalem, Israel) and Ioana Literat (Teachers College, Columbia University, USA).

(C) 2020 by the authors; licensee Cogitatio (Lisbon, Portugal). This article is licensed under a Creative Commons Attribution 4.0 International License (CC BY).

\section{Introduction}

On March 15, 2019, approximately 1.4 million protesters worldwide joined the youth strike for climate change (Barclay \& Amaria, 2019). The global climate strike was founded by Swedish teenager Greta Thunberg as a protest led by youth and younger generations to oppose past and current actions of older generations towards the environment. The strikes occurred over a series of Fridays, spanning more than one year, under the hashtag Fridays for Future. The March 15, 2019, event was the first time that the ongoing events drew more than 1 million protesters. Students went on strike and walked out of schools across the globe in order to draw attention to and encourage action on climate change. The strike continued into 2020; more youth protesters are taking to the streets in order to challenge governments and the media about the climate crisis. These protest initiatives followed similar grassroots-intensive blueprint used by other protest movements in recent years. This article examines 993 tweets with at least one \#SchoolStrike4Climate hashtag. We examine the spatial markings of the tweets (local, national, global), which demonstrated a pattern of connecting local action 
to global processes. We also examine the functions of the tweets (information, opinion, mobilization, or attacks), which reflected both support and criticism of the movement. As observed with other movements, the most common function was to share information and the least common function was to mobilize citizens to take action.

This article thus sheds light on the dynamics of collective/connective action among younger segments of the public as well as other civil society actors. It also offers a perspective about how youth are using social media while protesting and what kinds of reactions their protest generates from other members of society. Social media platforms are transforming political engagement by offering agency through the ability to voice political views. This research is important as action on climate change requires a global response. Social media can fill a gap in institutional processes which are not currently designed to engage citizens in global policy decisions. Social media can be used to question, contest, and/or support decisions or actions of media, political, private or governmental organizations related to the climate crisis. The global climate strike reflects a trend in international protest events, which are connected through social media and other digital media tools.

\section{Youth Activism}

There is a widespread concern about youth political participation in democratic countries, especially with regard to voting (Grasso, 2016; Martin, 2012; Sloam, 2016). Far from being apathetic, young people are more involved in other forms of engagement. These forms are ad hoc, issue-oriented, non-electoral, and personalized (Sloam, 2016; Vromen, Loader, Xenos, \& Bailo, 2016). However, this political activism could be used to influence government, as documented in the recent climate strikes (Pickard, 2019). In some countries, youth are more likely to engage in protest activities, but in other countries, there are minimal age differences or the patterns reflect generational political action repertories (Grasso, 2016; Martin, 2012; Sloam, 2016). Pickard (2019) calls this activism 'Do-It-Ourselves' politics, which uses a variety of tactics, including lifestyle choices, such as veganism and recycling, as well as climate strikes and non-violent direct action. Acting collectively is a key feature of this form of activism (Pickard, 2019).

Young people may use social media to express their political views. However, not all youth feel free to express their views online. Youth, as well as others, are reluctant to post their political views online, because of a fear of negative reactions or conflict, privacy concerns, and fear of posting something wrong (Bäck, Bäck, Fredén, \& Gustafsson, 2019; Thorson, 2014; Vromen et al., 2016). Yet, social media remain as popular forums for political expression. This form of activism is often regarded as slacktivism, instead of being viewed as an activity along a continuum of participation (Dennis,
2019). Furthermore, a meta-analysis demonstrates that these online activities are correlated with offline activities (Boulianne \& Theocharis, 2020). We expect to see youth using social media to express opinions, but we also expect to see others using social media to express opinions about youth and the global climate strike (Lievrouw, 2011; Pappacharissi, 2014). Digital media allows for political expression and this expression links individuals into a loosely organized network (Bennett \& Segerberg, 2012). In other words, "identity reference is more derived through inclusive and diverse large-scale personal expression rather than through common group or ideological identification" (Bennett \& Segerberg, 2012, p. 744). Thorson, Edgerly, Kligler-Vilenchik, Xu, and Wang (2016) illustrate this connective network in relation the 2014 People's Climate March.

\section{Climate Change}

The environmental movement has been described as the most influential and global movement of our time (Rootes, 2007). The nature of environmental issues requires a global lens, as environmental problems such as air pollution cannot be contained within political borders. Solutions require international collaboration involving governments and nonprofit organizations (Fisher \& Green, 2004). Furthermore, efforts to conserve resources, such as wildlife, also require global interventions, as demonstrated by the World Wildlife Fund. Indeed, the environmental movement is distinctive as a movement, because of the global scale and need for international collaboration (Rootes, 2007).

A major focal point of the current environmental movement is climate change. Public opinion research shows that concern about climate change fluctuates over time with key events triggering increased concern (Ballew et al., 2019; Brulle, Carmichael, \& Jenkins, 2012). Economic downturns, political elites, media coverage, availability of scientific information, weather changes, and activities of social movements/counter-movements have been considered as triggers for changing levels of concern about climate change (Benegal, 2018a; Brulle et al., 2012).

Concern about climate change is also marked by age, with young people more likely to express concern and believe in the anthropogenic origins of climate change (Arbuckle, 2017; Benegal, 2018a, 2018b; Hornsey, Harris, Bain, \& Fielding, 2016). In the US, even among Republicans, younger people 'worry' more about climate change, than their older counterparts (Republicans: $40 \%$ versus $28 \%$, Democrats: $86 \%$ versus 78\%; Ballew et al., 2019). Beyond the US, there are many studies documenting that young people are more concerned about climate change, compared to older people (Tobler, Visschers, \& Siegrist, 2012). In addition, age distinguishes those who are merely concerned from those who are 'concerned activists' in Germany (Metag, Füchslin, \& Schäfer, 2017). 


\section{Hashtag Activism}

The School Strike 4 Climate builds on existing movements and their use of social media, including the global Occupy movement (Theocharis, Lowe, van Deth, \& Garcia-Albacete, 2015), Arab Spring, and Idle No More (Raynauld, Richez, \& Boudreau Morris, 2017) as well as more youth-driven movements (see Raynauld, Lalancette, \& Tourigny-Koné, 2016, 2019; Theocharis, 2012). In addition, the social media tactics can reflect practices from more national or localized movements, such as the Black Lives Matter (Freelon, Mclllwain, \& Clark, 2016) and Euromaidan (MacDuffee-Metzger \& Tucker, 2017). These studies use hashtags to identify and analyze a discursive community around a particular topic. Jost et al. (2018) provide a summary of these movements.

These studies tend to find that Twitter is used largely for circulating information and rarely includes calls to action to engage in protest activities, following early work in this field (Theocharis et al., 2015). For example, using \#Ferguson, LeFebvre and Armstrong (2018) find that only $4 \%$ of tweets were calls for peaceful action, $2 \%$ of tweets were calls for digital action, and less than $1 \%$ were calls for violent action. Freelon et al. (2016) offer a big picture of 40 million \#BlackLivesMatter tweets, noting that invitations to participate were quite rare. Hodges and Stocking (2016) find that only $5 \%$ of tweets related to the Keystone $\mathrm{XL}$ pipeline involved a request to take action, such as signing a petition or protesting. In 2012, just 3\% of tweets about the Quebec student strike were recorded as having a mobilization function (Raynauld et al., 2016). In contrast, Raynauld et al. (2017) find that $14 \%$ of \#ldleNoMore tweets included details about mobilization. Following this line of research, we have similar expectations.

The infrequency of mobilization tweets is not indicative of the limited mobilization potential of social media, as studies of protesters find that social media use is a popular way to learn about a protest event (Fisher, 2019). Furthermore, many studies document a positive correlation between social media use and the likelihood of participation in protest (Boulianne, Koc-Michalska, \& Bimber, 2020). Social media platforms were critical to mobilizing participation in the March for Science in 2017 (Boulianne et al., 2020) as well as for young people in Chile during the 2011 environmental protest (Scherman, Arriagada, \& Valenzuela, 2015). There is a legacy of digital media being used to organize and mobilize participants in the environmental movement (Fisher \& Boekkooi, 2010).

As mentioned, most of the studies analyzing tweets conclude that the primary objective is to share information about the movement (Jost et al., 2018; LeFebvre \& Armstrong, 2018). Interviews with Black Lives Matter tweeters affirm that the motivation is to educate and raise awareness (Freelon et al., 2016). This information can be shared through links to traditional news sources and sharing photos of the event. Hyperlinks are popular in tweets, recognizing this core function (Jost et al., 2018; Merry, 2013; Pang \& Law, 2017; Raynauld et al., 2016, 2017).

Moving research forward, we recognize that the environmental movement is very much a global movement and as such, social media may be used differently. Pang and Law (2017) offer a review of Twitter-based studies in relation to the environmental movement. They explore how the inclusion of hyperlinks in tweets impact retweet patterns related to \#WorldEnvironmentDay, and examine how the use of visuals may persuade tweeters. Hodges and Stocking (2016) examine the Keystone XL pipeline Twitter discourse and find that supportive and oppositional groups make different uses of Twitter. Those who opposed the pipeline were more likely to interact with other Twitter users, share tweets about their views, and request donations (Hodges \& Stocking, 2016). Merry (2013) studied environmental groups on Twitter in the aftermath of the BP oil spill, and finds that $90 \%$ of tweets contained hyperlinks. She concludes that Twitter offers a new venue for conflict expansion and poses a problem for environmental groups trying to control the narrative around the BP oil spill (Merry, 2013). Thorson et al. (2016) explore how hashtags are used in the People's Climate March in 2014. They argue that the use of hashtags creates "a digital space of shared attention for the climate change march" (Thorson et al., 2016, p. 4791). This shared space is important for global protest events.

The key challenge for environmental action is that it requires local action to a global problem. This can lead to free-rider problems or bystander effects, where no one takes action. Individual actions might be perceived as inconsequential, given the global and overwhelming nature of environmental problems. This can deter environmentally friendly practices, as well as reduce the incentive to participate in marches and demonstrations, a high-effort activity. In the case of protests, if everyone can enjoy the benefits of a successful protest, then why would a single individual decide to incur the costs of participation (Jost et al., 2018)? Social media are believed to reduce the costs of participation, because information about the location and turnout are easier to acquire (Jost et al., 2018).

At the institutional level, environmental political action also poses a challenge. Democratic institutions are tied to nation-states, which are bounded to geographically-defined constituencies. Governments are held accountable by citizens within their country. However, the failure to address climate change has impact on global citizens, not just those citizens within one's country. Yet, global citizens do not have access to the global leaders that make decisions about climate change policies. Indeed, some global citizens are more vulnerable than others to the impacts of climate change, but their country may not be equipped to adapt to climate change (Sarkodie \& Strezov, 2019). For example, sub- 
Sahara Africa is often identified as a vulnerable region for climate change, but the governments in these countries have little control over the fate of global agreements on climate change (Sarkodie \& Strezov, 2019). As such, it is important to understand the global dimension to this activism. People are protesting in the streets to raise awareness of this issue at the local level as well as the global level in an effort to encourage global political action.

Social media present an opportunity to voice one's concerns about climate change and the need for action, as well as document the discontent among citizens by posting pictures of the protest event. Social media users may connect their local events to global events. In doing so, they are documenting their and others' discontent so that local political leaders can view their events virtually through social media images. However, they are also documenting their and others' discontent for global leaders to take note. Indeed, the spatial markings of protest events across the globe suggest that there is a global community concerned about climate change. Seeing this global community through protest images might help encourage action on climate change. Global citizens cannot participate in elections to choose global political leaders, nor can they participate in referendums to support climate change agreements. Social media offer a substitute for lacking global governance structures. As such, we are interested in the extent to which social media posts reflect this local-global tension. Our research questions are as follows:

RQ1: What are the spatial markings of tweets (local, national, global) related to \#SchoolStrike4Climate?

RQ2: What were the primary functions of tweets (information, opinion, mobilization, or blame) using \#SchoolStrike4Climate?

\section{Methods}

\subsection{Sample}

In order to systematically study how Twitter was used during the protests, the researchers decided upon several criteria for the sample. The choice of hashtags was based on Twitter trending topics statistics on the day of the event (approximately noon, mountain standard time, on March 15, 2019). At that time, these hashtags were trending: \#YouthClimateStrike (10.5K Tweets); \#ClimateActionNow (7K Tweets), and \#SchoolStrike4Climate (86.6K Tweets). \#FridaysforFuture was also trending, but unfortunately was not included in our subsequent scraping efforts. Indeed, this discursive network was difficult to capture, as the hashtag was also tweeted as "FridayforFuture" (missing the ' $s$ ') and sometimes 4 was used in lieu of "for." Nonetheless, this discourse was picked up through the use of multiple hashtags as many of our tweets included \#FridaysforFuture and \#SchoolStrike4Climate, as our findings demonstrate.
The data were scraped from Twitter using Netlytics (https://netlytic.org). Netlytics caps the scraps per query at 1,000 (most recent) tweets. As such, we chose a series of hashtags to scrape data and staggered the data collection process over time, beginning on March 15 at $16 \mathrm{~h}$ through to March 18 at 20h. These strategies allowed us to collect more than 35,000 tweets related to this event (tied to these various hashtags). We then turned our focus to the \#SchoolStrike4Climate, because it contained the largest number of tweets $(n=13,542)$. We narrowed the list by identifying the duplicates within the database. When identifying the distinctive tweets, we sorted these results from most to least frequent, then chose the most frequent/retweeted 1,000 from the 1,842 . Focusing on popularity/retweets helps capture the most common messages circulating around this event and the youth participants. Netlytic does not scrape the retweet/like metrics for individual posts. To compensate for this weakness, we added the metrics of the tweets that we quote, using estimates gathered as of December 9, 2019.

\subsection{Coding}

The number of tweets coded reflects recent practices in this field when using human coders (Pang \& Law, 2017; Raynauld et al., 2016, 2017, 2019). We coded 993 tweets into the following broad themes: spatial markings and function. Non-English tweets were translated using Google Translate and then coded. The diversity of languages and regions expressed in these tweets helped to gain a more global perspective in comparison to other hashtags. The codes were created in order to answer our research questions.

The coding of tweets employed the following process. The third author of this article coded tweets, then a second independent coder reviewed the tweets to agree/disagree with the original code, and finally, the first author of this article conducted a final review of each coded tweet. We did not conduct independent coding and as such, inter-coder reliability was not computed. Across all the function tweets, there were only 27 tweets (of 993) where the function was not clear across all three reviewers. In each case, the third reviewer/first author reviewed both coders' rationale and made the final decision. Changing all of these tweets into different functions would not change any of the core findings: Information was the most popular function, opinion was next, followed by attack, and mobilization was the least popular. To establish the validity of the coding scheme, we offer examples of tweets to exemplify each code. Because we are coding a subset of tweets defined by popularity, not randomness, we present statistics about patterns of relative frequency-which functions are more popular than others, rather than the precise percentage of tweets with a particular function in the entire discursive community related to \#SchoolStrike4Climate. These quantitative measures allow us to connect with the existing literature on functions. This approach also provides 
greater depth about what these functions entail, which is one of the contributions of this article.

As per RQ1, we are interested in the physical location of the protest event. As mentioned, participants in the Student Strike 4 Climate may feel an increased need to ground the movement in physical locations, by posting locations to Twitter. In addition, this practice highlights the global-local challenges of action related to environmental issues. To study mentions of location, we created seven categories for spatial location: 1) local; 2) national; 3) global; 4) local and national; 5) local and global; 6) national and global; and a combination of 7) local, national, and global. The spatial locations were the most straightforward to code. We coded for any reference to a location: a city (or a key location in a city, such as Buckingham Palace), a country, a region, for example. There were no disagreement per se, rather sometimes a marker was missed and this information was corrected. However, the correction rate was less than $1 \%$. Each coder could 'correct' the coding and offer a rationale for the change.

For RQ2, we used an existing coding scheme from the GGI codebook, which was originally developed to study the 2012 Quebec Student Protest (Raynauld et al., 2016, 2019). From this coding rubric, we adapted the original categories of information tweets, opinion tweets, mobilization tweets, and attack or denunciation tweets to fit this new strike. In line with prior applications of this coding scheme, these categories were treated as mutually exclusive to one another; if a tweet was interpreted as having two or more elements of these categories, it became the responsibility of the coder to determine which category best encapsulated the contents of the tweet. Within each function, we highlight subthemes of tweets. We ordered the subthemes in terms of most frequent to least frequent, without providing exact numbers, because the intent is to establish relative patterns, rather than exact estimates, which would require a larger random sample or the entire population of tweets using this hashtag.

The categories of information tweets were: tweet documenting the protest, tweet about an issue or event related directly to the strike, news reports related to the strike, and tweet sharing climate/environmental informa- tion. As mentioned, we present subthemes ordered from most to least frequent.

The opinion tweets category was broken down into subcategories: opinion about protest, opinion about climate change, opinion about youth protesters, and opinion about youth in general.

Expanding upon Merry (2013) and Hodges and Stocking (2016), who differentiate between online and offline forms of activism, we adjusted the mobilization category to distinguish between offline and online mobilization. The first category applied to attempts for 'traditional' offline forms of participation. Offline participation included activities like protesting, putting up flyers, and boycotting goods and industries. The second category was online mobilization requests, such as signing petitions and retweeting.

Like opinion tweets, attack tweets could pertain to a wide variety of topics, but unlike opinion tweets, attack tweets cannot express positive opinions: They condemn or denounce the actions of a person, group or social system. The first change we made to this category was to rename it to also include tweets which place environmental blame on particular groups or individuals. This change was influenced by Merry (2013). Using Merry's (2013) definition of blame, we created multiple categories for tweets that attack or create blame. In this paper, we focus on attacks or blame aimed at governments and attacks or blame aimed at media organizations. The purpose of these subcategories was to study how tweets attack or create blame and who or what is subsequently the target of these posts.

\section{Findings}

\subsection{RQ1: Spatial Markings}

We first wanted to see how location was mentioned in the tweets in order to understand the local-global dimension of this protest. The results showed that approximately 533 of 993 tweets mentioned a location (Table 1). Tweets that mentioned local protests were the most common (53.1\%). Local tweets mentioned towns or cities, including London, New York City, Paris, Montreal,

Table 1. Frequency and percent of spatial marking tweets.

\begin{tabular}{lrr}
\hline & Frequency & Percent \\
\hline Spatial marking & 533 & $53.7 \%$ \\
Local & 283 & $53.1 \%$ \\
Global & 98 & $18.4 \%$ \\
National & 64 & $12 \%$ \\
Local and global & 38 & $7.1 \%$ \\
Local and national & 25 & $4.7 \%$ \\
National and global & 11 & $2.1 \%$ \\
Local, national, and global & 9 & $1.7 \%$ \\
Other & 5 & $0.9 \%$ \\
No spatial markings & 460 & $46.3 \%$ \\
Total & 993 & $100 \%$ \\
\hline
\end{tabular}


Dublin, and Stockholm. They were followed by tweets mentioning the protest at a global scale (18.4\%), including this tweet by Greta Thunberg:

Tomorrow we school strike for the climate in 1769 places in 112 countries around the world. And counting. Everyone is welcome. Everyone is needed. Let's change history. And let's never stop for as long as it takes. \#fridaysforfuture \#schoolstrike4climate \#climatestrike [9,751 Retweets; 27,679 Likes].

The framing of this tweet creates a cosmopolitan image of protest rather than an image of protests located in a single city or country.

Tweets also connected the protest to the national level (12\%). These tweets referred to the countries in which the strikes occurred. Other tweets connected local cities to the global scale of the protest (7.1\%) and also connected local protests to protests across a nation state (4.7\%). Although these tweets create a similar cosmopolitan framing as tweets that framed the movement as global, it is worth noting that they were still attached to local and national spaces. There were relatively few tweets connecting local events to broader (national and global) events. These types of tweets would identify a specific city, the country, and link the event to the global events.

\subsection{RQ2: Function of Tweets}

The main focus of this research was to study the function of \#SchoolStrike4Climate tweets. The function of each tweet was broken into four variables with corresponding subcategories connected to each of the four larger variables. The first variable tested was information tweets. Information tweets had the highest frequency of occurrence (52.3\%; see Table 2 ). The next most popular category was opinion tweets $(29 \%)$, followed by attack/blame tweets (13.6\%). Finally, mobilization was not a popular function of tweets (4.8\%). As mentioned, the objective was not to establish precise estimates about the function of tweets, but to establish their relative frequency. As observed with other hashtag movements, information tweets were the most popular and mobilization the least popular.

In the next section, we take a qualitative look at how these functions were used to talk about the strike and the youth protesters and frame it/them in a positive or a negative light. We highlight subcategories for tweets that were most common within each of the function areas. The list of subcategories was ordered by frequency: The most frequently appearing subtheme in the dataset is listed first.

\subsubsection{Information Tweets}

Information tweets documented the protest, an issue or event related directly to the strike, news reports related to the strike, and shared climate/environmental information. The most popular type of information tweet was documentation of the protest, but offering little other information (see Table 2). Documentation tweets provided little actual detail about the protest beyond documenting location and size. For example: "Incredible!!

Table 2. Frequency and percent of tweet function categories.

\begin{tabular}{|c|c|c|}
\hline Function Categories & Frequency & Percentage \\
\hline $\begin{array}{l}\text { Information } \\
\text { Documentation tweet } \\
\text { Tweet about an issue or event related directly to the strike } \\
\text { News reports related to the strike } \\
\text { Climate/environmental information tweet }\end{array}$ & 519 & $52.3 \%$ \\
\hline $\begin{array}{l}\text { Opinion } \\
\text { Opinion about the protest } \\
\text { Opinion about climate change } \\
\text { Opinion about youth protesters } \\
\text { Opinion about youth }\end{array}$ & 288 & $29.0 \%$ \\
\hline $\begin{array}{l}\text { Attack/blame } \\
\text { Attack/blame at government } \\
\text { Attack/blame at media organization }\end{array}$ & 135 & $13.6 \%$ \\
\hline $\begin{array}{l}\text { Mobilization } \\
\text { Online mobilization requests } \\
\text { Offline mobilization requests }\end{array}$ & 48 & $4.8 \%$ \\
\hline Other (not about school strike or environment or youth or climate change) & 3 & $0.3 \%$ \\
\hline Total & 993 & $100 \%$ \\
\hline
\end{tabular}


Over one million students on school strike for the climate. \#FridayForFuture \#schoolstrike4climate" (581 Retweets; 1,390 Likes).

While there may be details lacking, this tweet conveys to the readers that over a million students are missing school in a global environmental protest. Even if documentation tweets did not convey a large quantity of information, their brevity might make them more accessible to readers. We might argue that sharing information about the strike can help bring attention to environmental issues since these tweets generally contained information like place and protest size. This tweet also exemplifies the ongoing issue with the Fridays for Future hashtag, which we mentioned in Section 5.1. This hashtag was difficult to track because sometimes ' $s$ ' is not used in the hashtag.

We also see, albeit less frequently, tweets that convey information about the strike, news reports about the strike, and information about climate change or environment. Tweets included updates about the number of participants and number of countries reporting strikes, including this tweet, also from Greta Thunberg: "According to https://t.co/pzYB6XuR6u we have already passed way over one million students on school strike today. Over 2000 places in 125 countries on all continents. And we have only just started! \#fridaysforfuture \#school strike4climate (picture from Prague, Czech Republic)" (6,401 Retweets; 18,688 Likes).

She also posted an update of this news: "Over 1,4mn on \#SchoolStrike4Climate yesterday according to latest update. 2083 places in 125 countries on all continents. "Biggest day of global climate action ever" says @350 And this isn't even the beginning. Because we have done our homework. \#FridayForFuture Pic: Montreal, CAN" (6,841 Retweets; 20,063 Likes).

Both of the above tweets included references to local events (Prague, Montreal, respectively), but connected these local events to the larger global event. Despite the tweet originating from @GretaThunberg's account, we note that the Friday for Future hashtag is missing the ' $\mathrm{s}$ ' in the example above.

In addition, tweets contained news about the strike, such as this tweet which included a video of protesters scaling the barricades: "'Police tried to close the entrance to The Mall leading to Buckingham Palace but they just keep on coming... \#ExtinctionRebellion \#climatestrike \#schoolstrike4climate,' @LdnRebellion. \#YouthStrike4Climate \#FridaysForFuture @Strike4Youth @UKSCN1 @ukycc" (207 Retweets; 420 Likes).

Information tweets sometimes went beyond simple information about the strike and presented the larger consequences of climate change. In this example, a professor of climate science at Potsdam University tweeted about a The New York Times article summarizing the science behind climate change: "The 20 warmest years on record have all come in the past 22 years, essentially the lifetime of today's children and young adults.' Great collection of images of \#school strike4climate \#ClimateStrike from around the world! https://www.nytimes.com/2019/03/15/climate/climateschool-strikes.html\#click=https://t.co/XQB2LmKYJL... \#FridaysForFuture \#Fridays4Future" (89 Retweets; 164 Likes).

Overall, the most popular function of tweets was to share information about the event. In particular, information tweets focused on documenting the size and location of events, with tweets from Greta Thunberg receiving a large number of reactions (retweets, likes).

\subsubsection{Opinion Tweets}

Opinion tweets were mostly related to opinions about the protest (Table 2). From these tweets, we see support as well as opposition to the climate strike. For example, this tweet was from the Global Warming Policy Forum and it was sharing a piece profiling a young girl who refused to go along with the strike: "Here's why I won't strike: One brave schoolgirl refuses to go along with the crowd and says climate strikers should 'first go study economics.' \#schoolstrike4climate \#ClimateStrike" (416 Retweets; 811 Likes).

In contrast, we see another tweet in which an Australian TV host Lee Constable (2019) wrote:

When I was at school we knew climate change was happening and climate action wasn't. We didn't strike. I stayed at school like a good girl so I could go be a scientist and solve it. Now l've got these degrees and I just wish we'd striked. \#Strike4Climate \#school strike4climate. (418 Retweets; 1,867 Likes)

Additionally, opinion tweets were often about climate change. They stressed the severity of environmental issues like climate change and often used these issues to frame the School Strike 4 Climate as protecting the future of the world. Tweets made claims like "not having a choice." This tweet from Sky News included a link to an interview with a teenager: "We do not have a choice, we have to act on climate now'@deespeak says she is a big fan of @GretaThunberg and completely supports the \#SchoolStrike4Climate movement. \#DeepOceanLive For more, head here: https://t.co/mE2xz5s65c" (25 Retweets; 66 Likes).

These tweets framed environmental issues as urgent and positioned the protesters as protagonists fighting for the future. They also bring an impression of urgency in relation to climate change.

The next most popular subcategory was tweeting about the youth protesters. In this example, the tweet was a meme with students using an extinguisher to stop a fire in the classroom, while the teacher is complaining that last week it was the climate strike and this week, a fire-students will do anything to skip school. The tweet was from a Swedish cartoonist: "The irresponsible climate activist youth of today! \#climechange \#climate \#FridaysForFuture \#earthstrike \#extinction 
rebellion \#RebelForLife \#ClimateCrisis \#Environment \#GreenNewDeal \#ClimateAction \#GretaThunberg \#schoolstrike4climate \#SchoolStrike \#schoolstrikefor climate" (588 Retweets; 1,679 Likes).

Opinions were also about youth. The 'brave schoolgirl' story made a reappearance in a tweet but this time with the annotation from a different tweeter that reads "Some young people think for themselves, some just follow the herd \#schoolstrike4climate" (154 Retweets; 407 Likes). As another example of negative opinions, a news report quoted the Australian Education Minister condemning the protest: "'Students leaving school during school hours (to protest) is not something to encourage, especially when they're being encouraged to do so by green political activists,' says Education Minister @DanTehanWannon \#SchoolStrike4Climate" (55 Retweets; 78 Likes).

It was difficult to code whether the opinion tweets expressed support or criticism for the strike, especially when the tweet was not in English.

\subsubsection{Attack/Blame Tweets}

Tweets with the function of attacking and blaming were the third most popular category (see Table 2). Approximately, $13.6 \%$ of tweets blamed someone or an institution, as the most popular attack/blame tweet targeted the government and government officials. Attacks directed at the government were often based on past discontent with government inaction, and a lack of faith and distrust for future promises of government action. US President Donald Trump was often at the center of the attacks. Many tweets simply have @realDonaldTrump, the number of participants in the specific event, and the hashtag. However, other politicians, including those in the UK and Australia were specifically mentioned. For example, this post was retweeted during our data collection period. The tweet originated with the account @ mac123_m, with 30,000 followers, and it criticized the UK's Tory government, specifically Michael Gove, and had a link to a The Guardian article:

The nine green policies killed off by the Tory govt. The Tories do not fight for the climate however much Michael Gove complains. Hope the young realise the way forward is with LAB \& their radical green policies. \#ClimateStrike \#SchoolStrike4Climate. (227 Retweets; 180 Likes)
Attack/blame tweets were directed at media organizations, especially the BBC. This tweet was posted by a UK magazine, Little Green Space, praising one media outlet and criticizing another media outlet. The tweet included a link to The Guardian report: "Great reports from @guardian on today's global \#SchoolStrike4Climate. Dear other UK media, including @BBCNews, there's a world beyond Brexit: ps give the 1000s of young people taking action the coverage they deserve and our planet needs. \#FridayForFuture https://t.co/aGSKh1NSbS" (95 Retweets; 177 Likes).

Again, we see that the hashtag for Friday for Future does not contain an 's,' making this hashtag a difficult focal point for a discursive community around this event.

\subsubsection{Mobilization}

Mobilization tweets comprised the smallest category of tweet functions (4.8\%; see Table 2). In these handful of tweets, online mobilization was more popular than offline mobilization. For example, Change.org UK posted an invitation to sign a petition with the fist-raised emoji, earth emoji, and the green heart emoji: "These students are fighting to save our planet es $\bigcirc 0$ Support their demand to declare a climate emergency here: https://t.co/9pGQBVfc6W \#YouthStrike4Climate \#SchoolStrike4Climate \#climatestrike \#climatechange \#Youth4Climate \#FridaysForFuture @GretaThunberg @Strike4Youth" (95 Retweets; 147 Likes).

As for mobilization to offline activities, Amnesty International posted a tweet explaining why people should participate: "Here are 5 reasons students (\& everyone else) should strike for climate. \#SchoolStrike4Climate" (395 Retweets; 681 Likes). These types of tweets were quite infrequent, as observed with other studies.

\section{Discussion}

As observed with other protest events, information was the most popular function of tweets and mobilization was the least popular. As mentioned, we borrowed the coding approach from Quebec Student Strike (see Raynauld et al., 2016, 2019) and \#ldleNoMore (see Raynauld et al., 2017). However, the results were largely the same. In all three studies, information tweets were the most frequent category recorded (see Table 3). Additionally, the percentage of opinion tweets and attack tweets were fairly similar. The biggest difference is that

Table 3. Percent totals of function categories for \#SchoolStrike4Climate, \#ggi, and \#IdleNoMore.

\begin{tabular}{lccc}
\hline Function categories & \#SchoolStrike4Climate (\%) & \#ggi (\%) (Quebec student strike) & \#IdleNoMore (\%) \\
\hline Information & $52.3 \%$ & $59 \%$ & $52 \%$ \\
Opinion & $29 \%$ & $28 \%$ & $16 \%$ \\
Attack & $13.6 \%$ & $10 \%$ & $10 \%$ \\
Mobilization & $4.8 \%$ & $3 \%$ & $21 \%$ \\
\hline
\end{tabular}


\#IdleNoMore tweets called for more mobilization, but this movement is distinctive compared to other movements (Freelon et al., 2016; Hodges \& Stocking, 2016; LeFebvre \& Armstrong, 2018; Theocharis et al., 2015).

Based on the similarities, we suggest that the uses of the Twitter platform for protest events have stabilized and, for now, no new uses could be observed. We have contributed to this scholarship by examining the nuances within these broad function categories. We also highlight the role of Twitter in documenting the size of these events. We also document the various types of opinions shared on Twitter and nuances about who is blamed for the climate crisis. This discourse moves beyond diagnosing the problem of climate change into discussions about who is responsible for solutions. As it was the case for the 2014 People's Climate March, we also saw different types of stakeholders come together in order to discuss the climate crisis and they were connected through a common hashtag (Thorson et al., 2016).

Twitter as a platform was used by the leader of the School Strike 4 Climate, Greta Thunberg. Her tweets were widely circulated, liked, and commented upon. However, we do not know the extent to which youth, more generally, are using this platform. We did not analyze the users who were tweeting about the strike; instead, we focused on the content being circulated. This content focused on youth. Aside from Greta Thunberg's tweets, every tweet used as an example included a mention of 'students,' 'youth,' 'young,' and 'school girl.' These examples represent the larger database of tweets, which included many mentions of these concepts as well as many @GretaThunberg references. In the larger database of 13,542 , the word 'students' appeared 33,000 times and @GretaThunberg appeared 20,000 times. Further research might consider who is tweeting and whether youth are using this platform (or another one) to express their views about climate change and the need for collective action. This information is difficult to acquire from Twitter profiles, which rarely mention age and often do not include a picture. However, since there was a clear leader and focal point for this movement, future research might consider using @GretaThunberg as a central node and examine the pattern of retweets around this node. This research could test the 'committed minorities' versus 'critical periphery' dynamic suggested by Barberá et al. (2015).

Another area for further study would be to study group identity. Hodges and Stocking (2016) note that group membership in modern social movements has become more liquid. As a result, movements like the School Strike 4 Climate are often viewed as collective action performed by individuals motivated by similar political or social interests and belief. \#SchoolStrike4Climate tweets should be analyzed over a longer period of time to see if Twitter users view themselves as part of a group. If individuals do indeed see the movement as a unified group, then it also becomes of interest to study times when group identity becomes more impor- tant and unified. Surveys and individual interviews with strikers would certainly help shed light on these questions. Rohlinger and Bunnage (2017) conducted interviews with Tea Party members over a two year period. These members were initially optimistic about social media use for "helping them cultivate a local political community...social media connected them with like-minded citizens and 'flattened' 'information hierarchies,' which allowed citizens to share information and engage in a conversation about it" (Rohlinger \& Bunnage, 2017, p. 8). Later, they became disillusioned with this media. They believed that the discourse on social media had been coopted by others, such as the Republican Party (Rohlinger \& Bunnage, 2017). Twitter may be co-opted by other interests, which may dampen youth leaders' enthusiasm for the platform. Furthermore, retweet networks within Twitter may drown the single youth's voice about why climate change is important and protest is an effective form of political participation. Research might examine these ideas-drawing on Rohlinger and Bunnage's (2017) work on Tea Party members-and also the changing tactics used by this movement over time, as well as whether the use of social media changes as a result of these changing tactics.

Our analysis contributed to the study of social media in protest events, highlighting the documentation feature which connects disparate local events to a larger movement. As we highlight the spatial markings that link local and global events, this becomes a unique feature of our research, which reflects the uniqueness of the environmental movement in terms of local actions for a global problem. We encourage others to pursue this line of research to examine the role of Twitter in connecting local experiences to global processes. Our analysis is also unique in highlighting reactions to this global climate strike. Social media platforms offer opportunities to express opinions about this event, youth leaders, and climate change as a policy issue. Social media can be used to facilitate a global discussion about this policy issue, which is important because action on climate change requires a global response. As mentioned, there were many tweets that contained US President Donald Trump's Twitter account and mentioned the size of the event. These tweets are intended to communicate with a global leader about the importance of climate change. Social media fill a void in governance structures, providing a mechanism to communicate with global leaders who do have the agency to act on climate change. Taking pictures of the event and circulating these images on social media can document the discontent experienced by global citizens who do not have other venues to express their views about climate change.

\section{Acknowledgments}

The authors would like to thank Vincent Raynauld for his guidance in setting up this project. 


\section{Conflict of Interests}

The authors declare no conflict of interests.

\section{References}

Arbuckle, M. B. (2017). The interaction of religion, political ideology and concern about climate change in the United States. Society \& Natural Resources, 30(2), 177-194.

Bäck, E., Bäck, H., Fredén, A., \& Gustafsson, N. (2019). A social safety net? Rejection sensitivity and political opinion sharing among young people in social media. New Media \& Society, 21(2), 298-316.

Ballew, M. T., Leiserowitz, A., Roser-Renouf, C., Rosenthal, S. A., Kotcher, J. E., Marlon, J. R., . . . Maibach, E. W. (2019). Climate change in the American mind: Data, tools, and trends. Environment: Science and Policy for Sustainable Development, 61(3), 4-18.

Barberá, P., Wang, N., Bonneau, R., Jost, J. T., Nagler, J., Tucker, J., \& González-Bailón, S. (2015). The critical periphery in the growth of social protests. PloS One, 10(11). https://dx.doi.org/10.1371\%2Fjournal. pone.0143611

Barclay, E., \& Amaria, K. (2019, March 17). Photos: Kids in 123 countries went on strike to protect the climate. Vox. Retrieved from https://www.vox.com/ energy-and-environment/2019/3/15/18267156/ youth-climate-strike-march-15-photos

Benegal, S. D. (2018a). The impact of unemployment and economic risk perceptions on attitudes towards anthropogenic climate change. Journal of Environmental Studies and Sciences, 8(3), 300-311.

Benegal, S. D. (2018b). The spillover of race and racial attitudes into public opinion about climate change. Environmental Politics, 27(4), 733-756.

Bennett, W. L., \& Segerberg, A. (2012). The logic of connective action: Digital media and the personalization of contentious politics. Information, Communication \& Society, 15(5), 739-768.

Boulianne, S., Koc-Michalska, K., \& Bimber, B. (2020). Mobilizing media: Comparing TV and social media effects on protest mobilization. Information, Communication \& Society. Advance online publication. https:// doi.org/10.1080/1369118X.2020.1713847

Boulianne, S., \& Theocharis, Y. (2020). Young people, digital media and engagement: A meta-analysis of research. Social Science Computer Review, 38(2), 111-127.

Brulle, R. J., Carmichael, J., \& Jenkins, J. C. (2012). Shifting public opinion on climate change: An empirical assessment of factors influencing concern over climate change in the U.S., 2002-2010. Climatic Change, 114(2), 169-188.

Dennis, J. (2019). Beyond slacktivism: Political participation on social media. Cham: Palgrave Macmillan.

Fisher, D. (2019). American resistance: From the women's march to the blue wave. New York, NY: Columbia University Press.
Fisher, D. R., \& Boekkooi, M. (2010). Mobilizing friends and strangers: Understanding the role of the Internet in the step it up day of action. Information Communication \& Society, 13(2), 193-208.

Fisher, D. R., \& Green, J. F. (2004). Understanding disenfranchisement: Civil society and developing countries' influence and participation in global governance for sustainable development. Global Environmental Politics, 4(3), 65-84.

Freelon, D., Mclllwain, C. D., \& Clark, M. D. (2016). Beyond the hashtags: \#Ferguson, \#Blacklivesmatter, and the online struggle for offline justice. Washington, DC: Center For Media \& Social Impact. Retrieved from https://cmsimpact.org/resource/ beyond-hashtags-ferguson-blacklivesmatter-onlinestruggle-offline-justice

Grasso, M. T. (2016). Generations, political participation and social change in Western Europe. London: Routledge.

Hodges, H. E., \& Stocking, G. (2016). A pipeline of tweets: Environmental movements' use of Twitter in response to the keystone $\mathrm{XL}$ pipeline. Environmental Politics, 25(2), 223-247.

Hornsey, M. J., Harris, E. A., Bain, P. G., \& Fielding, K. S. (2016). Meta-analyses of the determinants and outcomes of belief in climate change. Nature Climate Change, 6(6), 622-627.

Jost, J. T., Barberá, P., Bonneau, R., Langer, M., Metzger, M., Nagler, J., . . . Tucker, J. A. (2018). How social media facilitates political protest: Information, motivation, and social networks. Advances in Political Psychology, 39(Suppl. 1), 85-118.

LeFebvre, R. K., \& Armstrong, C. (2018). Grievance-based social movement mobilization in the \#Ferguson Twitter storm. New Media \& Society, 20(1), 8-28.

Lievrouw, L. A. (2011). Alternative and activist new media. Malden, MA: Polity Press.

MacDuffee-Metzger, M., \& Tucker, J. A. (2017). Social media and Euromaidan: A review essay. Slavic Review, 76(1), 169-191.

Martin, A. J. (2012). Young people and politics: Political engagement in the Anglo-American democracies. New York, NY: Routledge.

Merry, M. K. (2013). Tweeting for a cause: Microblogging and environmental advocacy. Policy \& Internet, 5(3), 304-327.

Metag, J., Füchslin, T., \& Schäfer, M. S. (2017). Global warming's five Germanys: A typology of Germans' views on climate change and patterns of media use and information. Public Understanding of Science, 26(4), 434-451.

Pang, N., \& Law, P. (2017). Retweeting \#WorldEnvironmentDay: A study of content features and visual rhetoric in an environmental movement. Computers in Human Behavior, 69, 54-61.

Pappacharissi, Z. (2014). Affective publics: Sentiment, technology, and politics. Oxford: Oxford University Press. 
Pickard, S. (2019). Young environmental activists are doing it themselves. Political Insight, 10(4), 4-7.

Raynauld, V., Lalancette, M., \& Tourigny-Koné, S. (2016). Political protest 2.0: Social media and the 2012 student strike in the province of Quebec, Canada. French Politics, 14(1), 1-29.

Raynauld, V., Lalancette, M., \& Tourigny-Koné, S. (2019). Rethinking digital activism as it unfolds: Twitterbased contention during the 2012 Quebec student strike. In M. Lalancette, V. Raynauld, \& E. Crandal (Eds.), What's trending in Canadian politics? Understanding transformations in power, media, and the public sphere (pp. 44-62). Vancouver: UBC Press.

Raynauld, V., Richez, E., \& Boudreau, M. K. (2017). Canada is \#ldleNoMore: Exploring dynamics of Indigenous political and civic protest in the twitterverse. Information, Communication \& Society, 21(4), 626-642.

Rohlinger, D., \& Bunnage, L. (2017). Did the Tea Party movement fuel the Trump-train? The role of social media in activist persistence and political change in the 21st Century. Social Media + Society, 3(2). https://doi.org/10.1177\%2F2056305117706786

Rootes, C. (2007). Environmental movements. In D. Snow, S. A. Soule, \& H. Kriesi (Eds.), Blackwell companion to social movements (pp. 608-640). Oxford: Blackwell Publishing.

Sarkodie, S. A., \& Strezov, V. (2019). Economic, social and governance adaptation readiness for mitigation of climate change vulnerability: Evidence from 192 countries. Science of the Total Environment, 656, 150-164. Scherman, A., Arriagada, A., \& Valenzuela, S. (2015). Stu- dent and environmental protests in Chile: The role of social media. Politics, 35(2), 151-171.

Sloam, J. (2016). Diversity and voice: The political participation of young people in the European Union. British Journal of Politics \& International Relations, 18(3), 521-537.

Theocharis, Y. (2012). Cuts, tweets, solidarity and mobilisation: How the internet shaped the student occupations. Parliamentary Affairs, 65(1), 162-194.

Theocharis, Y., Lowe, W., van Deth, J. W., \& GarciaAlbacete, G. (2015). Using Twitter to mobilize protest action: Online mobilization pattern and action repertoires in the Occupy Wall Street, Indignados, and Aganaktismenoi movements. Information, Communication \& Society, 18(2), 202-220.

Thorson, K. (2014). Facing an uncertain reception: Young citizens and political interaction on Facebook. Information, Communication \& Society, 17(2), 203-216.

Thorson, K., Edgerly, S., Kligler-Vilenchik, N., Xu, Y., \& Wang, L. (2016). Seeking visibility in a big tent: Digital communication and the people's climate march. International Journal of Communication, 10, 4784-4806.

Tobler, C., Visschers, V. H. M., \& Siegrist, M. (2012). Consumers' knowledge about climate change. Climatic Change, 114(2), 189-209.

Vromen, A., Loader, B. D., Xenos, M. A., \& Bailo, F. (2016). Everyday making through Facebook engagement: Young citizens' political interactions in Australia, the United Kingdom and the United States. Political Studies, 64(3), 513-533.

\section{About the Authors}

Shelley Boulianne is an Associate Professor in sociology at MacEwan University, Canada. She earned her PhD in sociology from the University of Wisconsin-Madison. She conducts research on media use and public opinion, as well as civic and political engagement, using meta-analysis techniques, experiments, and surveys. She has published in many journals, including New Media \& Society, Information, Communication \& Society, Political Communication, and Communication Research.

Mireille Lalancette is Full Professor of Political Communication at Université du Québec à Trois-Rivières. She conducts research on social media and political actors from politicians to interest groups and citizens. She is interested in mediatization of politics as well as gender and politics questions. She is also the editor of What's \#Trending in Canadian Politics? Understanding Transformations in Power, Media, and the Public Sphere (Vancouver: UBC Press, with V. Raynauld and E. Crandall). Her work has been published in Canadian and international research publications.

David Ilkiw is an Undergraduate Student in the Honours Sociology program at MacEwan University, Canada. His honours thesis explores the formation of collective memory in news publications. 